\title{
O CONCEITO DE FICÇÃO: O DIÁLOGO DE SAER COM ISER
}

Raquel Alves Mota - FALE/UFMG

A base da minha discussão será o ensaio de Saer ${ }^{1}$ "El concepto de ficción" inserido em obra homônima desse mesmo autor argentino, no qual defende algumas premissas que facilitam o entendimento de sua escrita literária. $\mathrm{O}$ ensaio condensa o pensamento saeriano, disperso em outros escritos críticos. Nele, há desde as primeiras linhas, a negação do par oposição: ficção versus verdade.

Aí, Saer enumera alguns obstáculos para a apreensão do conceito de verdade, mesmo em uma escrita que se nomeie como não-ficção; são eles: a autenticidade das fontes, os critérios interpretativos e a polissemia da própria construção verbal. Nesses obstáculos evidencia-se a relação tríade entre 0 indivíduo, o mundo (a realidade) e o texto. A realidade é discutida no primeiro obstáculo, quando Saer põe em dúvida a fidelidade das fontes que originam o texto não-ficcional, ou a capacidade destas para apreenderem o mundo, já que só é possível trabalhar com um recorte da realidade. Ademais, a subjetividade do investigador sempre delineará os contornos desse recorte, o que caracterizará o segundo obstáculo. Por último, a própria “combinação" dos elementos "selecionados" 2 permite uma gama de interpretações, o que pode anular a tática da intencionalidade.

Assim, Saer praticamente descarta a não-ficção como uma escritaverdade. Porém, através de uma escrita fugidia, que se nega a normatizar conceitos, "El concepto de ficción" - o que beira um paradoxo crítico - não esclarece os limites para os termos de sua escrita crítica. Ao invés disso, Saer procura jogar com os conceitos, esperando que seu leitor os conheça, ou os reconheça, por meio de uma

\footnotetext{
1 Este ensaio nasce da pesquisa que venho desenvolvendo sobre o escritor argentino: Juan José Saer. Saer nasceu em Santa Fé, em 1937. Exerceu a docência na Universidade do Litoral. Em 1968 estabeleceu-se em Paris, e também ali lecionou na Faculdade de Letras da Universidade de Rennes, França. Falece em 2005. Ademais de ter vários romances escritos, publicou alguns livros que reúnem seus ensaios críticos, nos quais discute, principalmente, o lugar da Literatura.

${ }^{2}$ Termos utilizados por Iser em "Os atos de fingir ou o que é fictício no texto ficcional”.
} 
discussão que já se processa nos caminhos da crítica literária. A base que utilizei, para a compreensão (dos conceitos de Saer), foram os escritos de Wolfgang Iser, que parecem mais profundos, na busca por uma "origem" dos conceitos, o que a torna mais teórica.

No âmbito dessa discussão, Saer nega a possibilidade da verdade estar no plano do objetivo, ou fora do âmbito do indivíduo, e, por conseguinte, desmente a ficção como o manifestar de um subjetivo puro, desvinculado de sua relação com o mundo. Para ele, a verdade não é o contrário da ficção. Assim, Saer deixa a verdade como par-oposição da ficção e se propõe a tratar dessa última. A ficção teria, então, um "caráter duplo": a mistura do empírico e do imaginário. Realidade e imaginação seriam os elementos que comporiam o campo do ficcional, em que o segundo elemento seria o responsável pelo alargamento do campo de ação do primeiro. Ou melhor: construindo-se na base de uma além-realidade, a imaginação teria a função de mostrar outras possibilidades para um dado recorte do mundo. A ficcionalidade dessa escrita se mostra por meio da não-permanência no campo da verdadeobjetiva. Há, aí, uma mescla entre o mundo e as variantes deste, perpassadas pelo crivo do criador-imaginador.

Voltando ao título deste trabalho, antes de continuar nessa tarefa de rever o texto de Saer, percebem-se ecos de Iser, ou, pelo menos, de alguns termos que utiliza, principalmente no ensaio "Os atos de fingir ou o que é fictício no texto ficcional". Neste, Iser busca dar novos contornos ao campo ficcional. Rejeita a sua oposição à realidade, pois esta faria parte da própria constituição do ficcional, juntamente com o imaginário. Iser rechaça a oposição entre realidade e ficção, que Saer também descarta. Para o primeiro, o recorte da realidade ganha outro estatuto, quando dentro do espaço do texto, devido aos mecanismos de disposição e de reorganização a que ele está sujeito nesse novo ambiente. Dessa forma, a ficcionalidade se desvela, provocando o efeito do imaginário, porque:

Como o texto ficcional contém elementos do real, sem que se esgote na descrição deste real, estão o seu componente fictício não tem o caráter de uma finalidade em si mesma, mas é, enquanto fingida, a preparação de um imaginário. ${ }^{3}$

\footnotetext{
${ }^{3}$ ISER. Os atos de fingir ou o que é fictício no texto ficcional. 2002, p. 957.
} 
Quero, aqui, deter-me, pois a principal diferença entre os dois críticos está na concepção de imaginário, ou na sua concretização. Iser defende o imaginário priorizando o seu aspecto de efeito; ou seja, como produto da recepção, determinado pelos próprios elementos do texto. Em outro polo, Saer defende o imaginário exclusivamente como elemento constitutivo da ficção, como um dos materiais que conformam o texto ficcional. Assim, em Saer permanece a dualidade na formação do ficcional, como em trechos com este:

Aun aquellas ficciones que incorporan lo falso de un modo deliberado fuentes falsas, atribuciones falsas, confusión de datos históricos con datos imaginarios, etcétera, lo hacen no para confundir al lector, sino para señalar el carácter doble de la ficción, que mezcla, de un modo inevitable, lo empírico y lo imaginario. ${ }^{4}$

A partir disso, vê-se que Saer prioriza a constituição do texto; ou seja, o imaginário pertence ao autor, ao processo de feitura da obra. A relação do homem com o mundo se desenvolve na conjunção do acontecido com o que poderia acontecer, segundo a capacidade imaginativa do autor. Parece que, aqui, Saer volta ao dualismo homem versus mundo, que tinha sido rechaçado em outra parte do texto, dada a impossibilidade de reescrever esse mundo isolado do homem. A ficção se mostra como esse conjunto do empírico-objetivo e das variantes de uma interpretação do sujeito criador.

Em Iser, o ficcional não é uma junção de elementos, como algo palpável, mas como acontecimento. É a representação de um processo a que é sujeito um dado recorte da realidade que, desvinculado de sua origem, ganha novas conotações dentro do novo espaço: o texto. Essa garantia de ficcionalidade revelase pelo rearranjo dos elementos, gerido pelas forças que agem no texto, representadas pelos "atos de fingir".

Não descartando o olhar de Saer para o leitor, percebe-se a centralidade que recebe a instância autoral, na sua recepção. Aceita-se o gerir da intenção no processo de leitura da obra, o que pode filiá-lo ao pensamento de Gumbrecht que, em “As Conseqüências da Estética da Recepção: Um Início Postergado”, defende,

\footnotetext{
${ }^{4}$ SAER, 1997.
} 
com cinco razões ${ }^{5}$, a intenção do autor como pano de fundo ${ }^{6}$ para a validade de outras interpretações possíveis. O texto perde essa função; ou melhor, perde a sua independência em relação à intencionalidade, e há quase uma unificação das duas instâncias.

Gumbrecht, que, em um primeiro momento, polariza uma história da recepção em uma normativa e, outra, descritiva: posteriormente, aceita uma normatividade dentro da própria história descritiva, quando aponta a intencionalidade como centro de referência de leitura. Esse pensamento se esclarece quando relacionado ao "horizonte de expectativa" de Jauss que, na procura pela história da leitura, propõe que se procure a heurística entre o autor e o primeiro público da obra como base para o entendimento do processo de recepção, considerando que:

a literatura como acontecimento cumpre-se primordialmente no horizonte de expectativa dos leitores, críticos e autores, seus contemporâneos e pósteros, ao experienciar a obra. Da objetivação ou não desse horizonte de expectativa dependerá, pois, a possibilidade de compreender e apresentar a história da literatura em sua historicidade própria. $^{7}$

A premissa do ensaio de Gumbrecht pode ser assim resumida: toda escrita, mesmo a autobiográfica, requisita a presença de um interlocutor. A proposta é a busca da heurística pelo autor, já que é por meio dele que se torna possível visualizar a que leitor o texto se direciona. Esse pensamento se baseia na defesa de uma crítica literária vinculada à Sociologia da Comunicação; ou seja, à relação entre estrutura social, ação social e atos comunicativos. Sob essa égide, há o imperativo para que o texto mantenha o seu significado social, evitando que se renegue o seu contexto de criação - ou a relação postulada nesse processo: “[...]

\footnotetext{
${ }^{5}$ As cinco razões, enumeradas por Gumbrecht, podem ser assim sintetizadas: $1^{\mathrm{a}}$ ) o significado pretendido pelo autor pode ser facilmente reconstituído. $2^{\mathrm{a}}$ ) A reconstrução do contexto de produção é relevante para vários tipos de crítica ideológica e textual. $3^{\mathrm{a}}$ ) O significado pretendido pelo autor vincula-se ao campo da produção histórica e recepção literária contemporânea. $4^{\mathrm{a}}$ ) Os leitores são capazes de reconstituir o plano de ação do autor. $5^{a}$ ) A concepção sociológica de ação poderia ser uma forma de superar a cisão no campo da crítica literária. (GUMBRECHT, 1998, p. 27-28). ${ }^{6}$ No referido texto, Gumbrecht escreve: "[...] eu gostaria de recomendar a utilização do significado pretendido pelo autor como o fundo contra o qual outros significados podem ser compreendidos e comparados". (GUMBRECHT, 1998, p. 27).

7 JAUSS, 1994, p. 26.
} 
logo que os textos sejam lidos, sem qualquer suposição sobre o contexto de sua produção, eles não são mais entendidos como ações" (GUMBRECHT, 1998, p.31).

Deslocando-se desse pensamento, Iser propõe a recepção como efeito, ${ }^{8}$ como acontecimento único, ocorrido entre o leitor e sua leitura. Negando a busca pelo sentido - como algo que poderia ser subtraído do texto, reduzindo a sua dimensionalidade -, Iser defende a relação performática ${ }^{9}$ do leitor com o texto, argumentando que:

o sentido como efeito causa impacto, e tal impacto não é superado pela explicação, mas, ao contrário, a leva ao fracasso. O efeito depende da participação do leitor e sua leitura; contrariamente, a explicação relaciona o texto à realidade dos quadros de referência e, em conseqüência, nivela com o mundo o que surgiu através do texto ficcional. ${ }^{10}$

Iser, em "Os atos de fingir ou o que é fictício no texto ficcional”, reclamando a leitura como concretização da obra, antecipa o imaginário como integrante do ficcional, ciente de que este se manifestará na configuração do ficcional (no ato de rearranjo) e, posteriormente, como efeito, ou no ato de recepção. Nesse esquema, defende-se a relação tríade entre realidade, ficção e imaginário, como elementos constitutivos do ficcional, nestes termos:

assim o ato de fingir ganha a sua marca própria, que é de provocar a repetição no texto da realidade vivencial, por esta repetição atribuindo uma configuração ao imaginário, pela qual a realidade repetida se transforma em signo e o imaginário em efeito do que é assim referido. ${ }^{11}$

Com os três atos de fingir, Iser gesticula esta relação: a seleção, a combinação e o autodesnudamento seriam o motor que impulsionaria o funcionamento e a existência do próprio texto ficcional, incidindo no seu caráter fictício, ou, em outras palavras, gerando esse atributo ficcional. Assim, o atributo ficcional do texto se comporia dos "atos de fingir" - e por meio da ação deles. A

\footnotetext{
${ }^{8}$ Gumbrecht, em dado momento de seu texto, retoma o pensamento iseriano, quando detecta a inviabilidade de se reescrever o contato do leitor com o texto - o efeito da recepção. Continua, porém, solidário à Sociologia da Comunicação como base para uma crítica literária.

9 Em contraposição à representação aristotélica, Iser, em "O Jogo do Texto", defende a reformulação dos elementos do texto através de um ato performativo, em um sistema que se abre para as variações do acontecimento.

${ }^{10}$ ISER. O ato de leitura. 1996, p. 34.

"ISER. Os atos de fingir ou o que é fictício no texto ficcional. 2002, p. 958.
} 
"seleção" agiria sobre o texto e o contexto, a "combinação", sobre o texto, e, ambas, para a realização do imaginário. $\mathrm{O}$ último ato de fingir, $\mathrm{O}$ autodesnudamento, seria a afirmação do estatuto ficcional do texto: "o como se".

Saer delineia o terceiro "ato de fingir" de Iser, na tentativa de aproximar e, ao mesmo tempo, afastar o texto do contexto: “[...] la ficción no solicita ser creída en tanto que verdad, sino en tanto que ficción". ${ }^{12}$ Dessa forma, a ficção se auto-intitula para, com liberdade, poder atravessar os limites do mundo. Para exemplificar essa relação, Saer busca contrastar dois extremos: Solienitsin, com o realismo socialista - com o objetivo de fotografar um dado acontecimento - versus Umberto Eco, que reclama o falso. O paradigma de Saer é Jorge Luis Borges, que, negando o contraponto - verdade $\mathrm{x}$ ficção -, prefere argumentar as variantes que eclodem nessa relação, ou o seu teor paradoxal, porque, ao mesmo tempo em que o texto ficcional afirma-se como ficção, ele quer ser absorvido como verdade.

Após isso, Saer chega à conclusão de seu ensaio, ao conceito de ficção. A ficção se mostra como uma "Antropologia Especulativa", devido à soma de forças que compõem sua natureza: seu conturbado apelo fictício (devido ao teor paradoxal, explorado no parágrafo acima), sua intenção, sua resolução prática, e a "posición singular de su autor entre los imperativos de un saber objetivo y las turbulencias de la subjetividad". ${ }^{13}$ Esse conceito demonstra o foco crítico de Saer na criação literária: ou seja, buscar as medidas do ficcional teria como base o entendimento da ação da intencionalidade, os esquemas que demandam a urdidura da obra literária.

Entender a ficção seria, por conseguinte, visualizar esse momento de criação, perceber a relação do autor com o contexto, atravessado pelo seu próprio saber, por sua subjetividade. Saer não oblitera o conceito, chega-se ao final do ensaio (Saer desenvolve a discussão anterior, da relação ficção-verdade, para, ao final, lançar o conceito) e o que se percebe é a recusa a se delimitar o seu horizonte. Pelo que foi dito, a "Antropologia Especulativa" relaciona-se com o tratamento do homem pelo homem, enfocando as artimanhas que advêm da sua relação com o mundo, o que vem a ser retratado dentro de um espaço livre - o texto - em que se

\footnotetext{
${ }^{12}$ SAER, 1997.

${ }^{13}$ Ibidem.
} 
pode emergir nas muitas possibilidades, pois a Literatura, despreocupada com uma solução, aposta em um discurso amplo, que se entrega à diversidade de respostas.

Depois de percorrer o ensaio de Saer, pude, não ocultando suas referidas semelhanças e dessemelhanças com "Os atos de fingir ou o que é fictício no texto ficcional", trazer, novamente, Iser. Em outro ensaio, intitulado "O que é antropologia literária?", Iser desenvolve esse conceito, que relembra o de Saer. Primeiramente, há o esclarecimento do que seria a ciência antropológica, para que se perceba, após isso, um possível viés literário. Nesse esquema, Iser defende a Antropologia - como outras ciências - como possuidora de uma "implicação teórica", de uma escrita que persegue a descrição de um processo, com o fim de suplantar os vazios - entre os fatos empíricos - com a articulação dos vestígios encontrados, por meio da explicação teórica.

O homem é um artefato cultural, ao mesmo tempo em que produz cultura. Sendo a Literatura parte da cultura, ela denuncia a sua "dimensão antropológica própria”, posto que a cultura é o objeto principal dos estudos antropológicos. Iser retoma os conceitos defendidos em "Os atos de fingir ou o que é fictício no texto ficcional", afirmando que a Antropologia (como outras ciências) se desdobra para produzir um roteiro teórico que justifique os vazios de um saber objetivo. Esse relato, tendo um caráter de artifício, "algo moldado", recebe a designação de ficção: tudo passa a ser ficção. Ou seja, é ficção pelo seu caráter de relato produzido, articulado, e não por ser falso. A Literatura se diferenciaria desse grupo por se denunciar "como se" fosse verdade, por meio do terceiro ato de fingir: o autodesnudamento.

Dessa discussão nasce o contraponto: ficções explicativas versus ficções literárias. A segunda quer ser absorvida como verdade, apesar de se apoiar na relação do "como se"; já a primeira cria relatos para suprir os vazios que permeiam os fatos concretos. As ficções literárias, por se apoiarem na tríade: ficção, realidade e imaginário, e não apenas em uma realidade-objetiva, dependem do autodesnudamento, para que ela não se torne mito. Dito isso, a ficção se caracteriza por “representar a ausência": aquilo que precisa de uma reformulação.

As ficções literárias criam, então, um novo espaço para se articularem, como realidade posta em parênteses. Decompõem e recompõem as organizações 
existentes fora do texto - via seleção e combinação -, por meio de uma forma própria, altamente livre. Através disso, há uma formação de hiatos no texto; ou seja, um movimento contrário ao das ficções explicativas, o que permite o "jogo do texto", no seu encontro com o leitor. Assim, as ficções explicativas são integradoras do caos do mundo, porque trabalham na reorganização do próprio texto-mundo. A diferença maior seria que, nestas, há uma tentativa de continuar o mundo: não se requer uma mudança de estatuto. O espaço do texto não é apresentado como um topos diferente, mas como um contínuo do seu próprio contexto.

A “Antropologia Literária” não se aloca dentro da ciência antropológica, já que a Literatura reclama um tratamento próprio, dada a especificidade da articulação de seus componentes. Por isso, a Antropologia serve como possibilidade de enxergar o homem na relação autor-texto-leitor. O texto literário, na sua tríade constitutiva, trabalha o homem: a intencionalidade na relação com o mundo gera um texto que, no contato com o "leitor-homem", produz um imaginário, como efeito dessa relação; e:

duas premissas são para isso essenciais: 1. Não se pode deduzir a heurística doutras disciplinas e depois impô-la à literatura. 2. Apesar de seu caráter de construto, a heurística deveria apoiar-se em disposições humanas que são ao mesmo tempo também constitutivas para a literatura. Isso é válido tanto para a ficção, quanto para o imaginário. Ambos os fenômenos existem como experiência de evidência $[. . .]^{14}$

Cotejando-se os dois conceitos - Antropologia Especulativa e Antropologia Literária -, percebe-se que Saer, com o primeiro, propõe-se, basicamente, a buscar as relações que demandam a criação literária. Quando lança o conceito, apresenta quatro fatores que o caracterizam, sendo que apenas o primeiro deles poderia trazer maiores dúvidas contra essa filiação: o aspecto específico do relato fictício. Porém, levando-se em conta o que foi discutido anteriormente - a dualidade presente na constituição do ficcional de Saer, a mescla entre realidade e imaginário advindas da intervenção do autor -, esse risco se rompe.

\footnotetext{
${ }^{14}$ ISER. Prefácio. 1996, p. 11.
} 
Os outros três fatores apresentados por Saer, são: a intenção do relato, a resolução prática e a posição do autor no entrecruzamento entre o mundo e a sua subjetividade. Dentre esses, apenas o segundo foge a uma determinação mais específica, já que Saer não explicita tais conceitos. Não há como saber se, aqui, ele reclama ou defende a Literatura como possível influenciadora da recepção, ${ }^{15}$ conferindo-Ihe um caráter prático como função. Os outros dois fatores, porém, sujeitam-se aos desmandos de uma intencionalidade.

$\mathrm{Na}$ “Antropologia Literária” de Iser, o homem é também percebido no texto; ou seja, como resultado de um trabalho cultural, como parte do universo da Arte. Aqui, "a ficcionalidade na literatura funciona basicamente como meio de exploração", ${ }^{16}$ segundo Iser. Assim, o que foi discutido, anteriormente, a respeito do conceito de Literatura de Iser, torna-se importante para compreender a “Antropologia Literária”; ou seja, essa atividade de exploração. Voltando ao que já foi dito, na relação tríade entre os elementos da Literatura, percebe-se a ênfase que Iser deposita na recepção. O seu conceito de antropologia está dentro desse esquema, ou seja, na relação com o leitor, no processo de efeito estético. Iser nega, veementemente, a possibilidade de o mundo presente no texto ser confundido com o mundo real. Essa relação se concretiza apenas com o objetivo de o texto ser compreendido, ou, em suas palavras, como possibilidade de "tornar-se perceptível". ${ }^{17}$ Ao mesmo tempo em que o texto remete a essa relação com o mundo, e então, com o homem, seu foco deve estar na sua concretização receptiva - quando já constituído como ficção -; ou seja, na interação com o leitor.

\footnotetext{
${ }^{15}$ Jauss em A história da literatura como provocação à teoria literária, discute, na tese XII, a Literatura com essa função social.

${ }^{16}$ ISER. O que é Antropologia Literária? 1999, p. 167.

${ }^{17}$ ISER. Os atos de fingir ou o que é fictício no texto ficcional. 2002, p. 977.
} 


\section{REFERÊNCIAS}

CASTRO ROCHA, João Cezar (Org.). Teoria da Ficção: indagações à obra de Wolfgang Iser. Rio de Janeiro: UERJ, 1999.

COSTA LIMA, Luiz. Teoria da literatura em suas fontes. 2. ed.. Rio de Janeiro: Francisco Alves, 2002. v. 2, p. 955-987.

COSTA LIMA, Luiz (Org.). In: A literatura e o leitor. 2. ed.. Rio de Janeiro: Paz e Terra, 2002.

COSTA LIMA, Luiz. Teoria da literatura em suas fontes. 2. ed.. Rio de Janeiro: Francisco Alves, 2002.

GUMBRECHT, Hans Ulrich. As conseqüências da Estética da Recepção: um início postergado. In: . Corpo e forma. Rio de Janeiro: UERJ, 1998. p. 23-46.

ISER, Wolfgang. Situação do problema. In: . O ato de leitura: uma teoria do efeito estético. São Paulo: 34, 1996. v. 1, p.21-98.

ISER, Wolfgang. Prefácio. In: - O fictício e o imaginário. Rio de Janeiro: UERJ, 1996. p. 7-12.

ISER, Wolfgang. Os atos de fingir ou o que é fictício no texto ficcional. In: COSTA LIMA, Luiz. Teoria da literatura em suas fontes. 2. ed.. Rio de Janeiro: Francisco Alves, 2002. v. 2, p. 955-987.

ISER, Wolfgang. O jogo do texto. In: COSTA LIMA, Luiz (Org.). 2. ed.. Rio de Janeiro: Paz e Terra, 2002. p. 105-118.

ISER, Wolfgang. O que é Antropologia Literária? In: CASTRO ROCHA, João Cezar (Org.). Rio de Janeiro: UERJ, 1999. p.147-178.

JAUSS, Hans Robert. A história da literatura como provocação à teoria literária. Tradução de Sérgio Tellaroli. São Paulo: Ática, 1994.

SAER, Juan José. El concepto de ficción. In: . El concepto de ficción. Buenos Aires: Seix Barral, 1997. 